\title{
Experimental Research on Acoustic Emission Characteristics of High Performance Concrete Beam with $\mathrm{Nano} \mathrm{SiO}_{2}$
}

\author{
Lan Yan ${ }^{1, a}$, YongMing Xinga ${ }^{2, b}$ and ZhanYun $\mathrm{Gao}^{3, \mathrm{c}}$ \\ ${ }^{1}$ School of Science, Inner Mongolia University of Technology, Hohhot 010051, China \\ ${ }^{2}$ Department of Civil Engineering and Architecture, Hohhot Vocational College,Hohhot \\ 010058,China \\ ${ }^{3}$ School of Science, Inner Mongolia University of Technology, Hohhot 010051, China \\ ayanlanyl@163.com, ${ }^{b}$ xym xing@163.com, ${ }^{\mathrm{C}}$ hzygzy@tom.com
}

\begin{abstract}
Keywords: High performance concrete ; Mechanical properties ; Acoustic emission ; 3D positioning; initial cracking point

Abstract. Variations in the acoustic emission parameters of normal concrete (NC), steel fiber reinforced concrete (SFRC), and nano $\mathrm{SiO}_{2}$ fiber concrete (NSFC) with the increase in loads under four-point bending load were studied. Distribution law of acoustic emission signals and its correlations with flexural strength and breaking energy of the concrete were discussed. The energy jump of acoustic emission (AE) signals reflects abrupt changes in the load and displacement of specimens. The first change point on the time of arrival (TOA)-energy curve corresponds to the load and displacement of the initial cracking point of the load-displacement curve. Nano $\mathrm{SiO}_{2}$ significantly enhances the strength of AE signals, thereby prolonging the duration of an AE event. An extended $\mathrm{AE}$ event is conducive to accurately determining the initial cracking point. Compared with steel fiber-reinforced concrete (SFRC), nano $\mathrm{SiO}_{2}$ steel fiber-reinforced concrete (NSFC) exhibits greater toughness and bending strength. The addition of nano $\mathrm{SiO}_{2}$ leads to a more stable $\mathrm{AE}$ test result, which is beneficial for identifying the initial cracking point and critical failure point of a concrete beam, determining the initial load and ultimate bearing capacity of the beam, and providing an early warning against possible structural failures.
\end{abstract}

\section{Introduction}

Acoustic emission (AE) is a natural phenomenon wherein materials or structures release strain energies through elastic waves upon deformation or damage under external or internal stresses[1-2]. AE technology evaluates material performance by analyzing its AE characteristics and forming timely responses to dynamic changes of micro damage energies of the material. The technology reflects material safety under load bearing directly, thereby enabling the provisions of early warnings of possible failures[3-5].

With application of nanotechnology in concrete in recent years, developing high performance concrete with multiple functions is now possible. Nanomaterials have small size, quantum, surface, and interface effects, characteristics which are absent in macro objects, and provide nanomaterials with special structures and physical and chemical properties [6-7]. Similar to the AE mechanism of other materials, the $\mathrm{AE}$ of concrete is the consequence of dislocation motion of crystals, relative slippage between crystals, elastic and plastic deformations, crack development and extension, and friction [8]. Doon-Jin Yoon pointed out that the damaged state of concrete could be evaluated by analyzing AE parameters and waveforms [8].

Health monitoring of structures or components is one of the most important use of $\mathrm{AE}$ technology, which is a dynamic non-destructive monitoring method. This paper studied variations of $\mathrm{AE}$ parameters of nano $\mathrm{SiO} 2$ fiber concrete (NSFC) with the increase of loads under four-point 
bending load. Positioning analysis of damage evolution on a high-performance concrete beam was conducted by using AE technology. AE positioning and stress-stain curves after the failure of the small beam samples were analyzed. The distribution law of AE signals and their correlation with flexural strength and breaking energy of the concrete were also explored.

\section{Testing Materials, Apparatus, and Method}

\section{Raw Materials}

The materials used in this study included 42.5-Class ordinary Portland cement, stones with particle sizes ranging from $5 \mathrm{~mm}$ to $20 \mathrm{~mm}$, sand with medium particle sizes and under continuous gradation, as well as steel fiber (arch high-strength steel wire with a length of $35 \mathrm{~mm}$, equivalent diameter of $0.6 \mathrm{~mm}$, length diameter ratio of 58 , and volume rate of $1.5 \%$. The nano- $\mathrm{SiO}_{2}$ concrete used in this study was obtained from Hangzhou Wanjing New Material Co. Ltd. The mixing amount of nano- $\mathrm{SiO}_{2}$ was only $2 \%$ of the cementing materials that substitutes the same amount of cement. The concrete strength was C50. Table 1 shows the technical parameters and Table 2 shows the mix design.

Table1 Properties of $\mathrm{Nano}_{-} \mathrm{SiO}_{2}$

\begin{tabular}{cccccccc}
\hline Content & $\begin{array}{c}\text { Purity } \\
/[\%]\end{array}$ & $\begin{array}{c}\text { Average particle } \\
\text { size } /[\mathrm{nm}]\end{array}$ & $\begin{array}{c}\text { Apparent } \\
\text { density/[g/L] }\end{array}$ & $\begin{array}{c}\mathrm{PH} \\
\text { value }\end{array}$ & $\begin{array}{c}\text { Specific } \\
\text { surface area } \\
/\left[\mathrm{m}^{2} / \mathrm{g}\right]\end{array}$ & $\begin{array}{c}\text { Ignition } \\
\text { loss/ [\%] }]\end{array}$ & Appearance \\
\hline Properties & 99.5 & 30 & $40-60$ & $5-7$ & $200 \pm 10$ & $\leq 1.0$ & $\begin{array}{c}\text { Non-crystal } \\
\text { White powder }\end{array}$ \\
\hline
\end{tabular}

Table2 Mix proportions and compressive strength of different concretes prepared

\begin{tabular}{ccccccccccc}
\hline & \multicolumn{10}{c}{ Mix proportion $/\left[\mathrm{kg} \cdot \mathrm{m}^{-3}\right]$} \\
\cline { 2 - 10 } Sample & Cement & Fly ash & Sand $\begin{array}{c}\text { Coarse } \\
\text { aggregate }\end{array}$ & Water & Nano-SiO ${ }_{2}$ & $\begin{array}{c}\text { Steel Water reducing } \\
\text { fiber }\end{array}$ & $\begin{array}{c}\text { Slump } \\
\text { agent }\end{array}$ \\
\hline NC & 420 & 110 & 668 & 1044 & 165 & 0 & 0 & 17.6 & 200 \\
\hline SFRC & 420 & 110 & 622 & 973 & 165 & 0 & 117 & 17.6 & 50 \\
\hline NSFC & 411.6 & 110 & 622 & 973 & 165 & 8.4 & 117 & 17.6 & 25 \\
\hline
\end{tabular}

\section{Experimental apparatus}

In this experiment, beam specimens with dimensions of $100 \mathrm{~mm} \times 100 \mathrm{~mm} \times 400 \mathrm{~mm}$ were used, and one experimental group consisted of three specimens.After $28 \mathrm{~d}$ of standard curing, all test pieces were dried and their flexural strength tested using a WAW-800 microcomputer controlled electro-hydraulic servo universal tester. The AE monitoring test was conducted simultaneously. The AE detector used SDAES AE detection system (Beijing Shenghua Technology Co., Ltd) which is composed of hardware (sensor, preamplifier, AE collection card and computer), system software, and

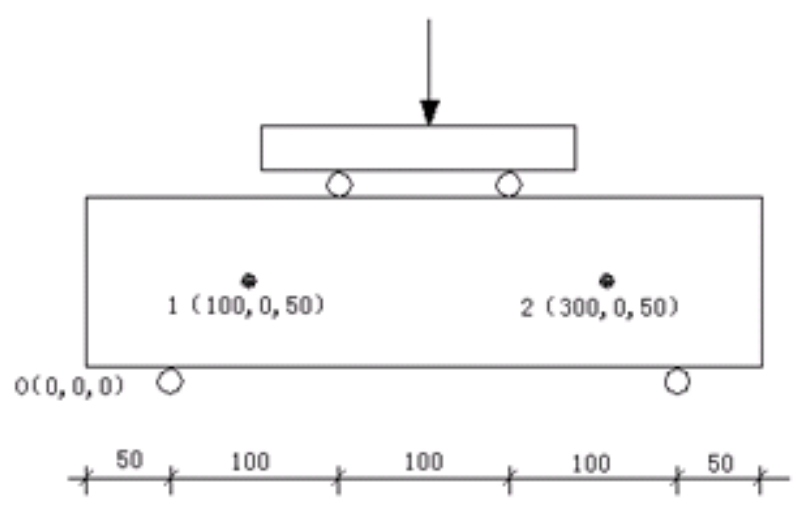

Front

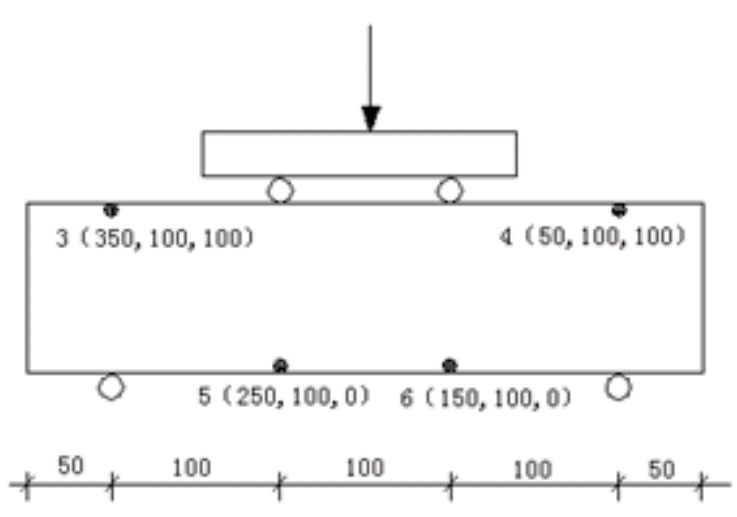

Back elevation

Fig.1 The schematic diagram of sensor position 
special software. The sensor model is Nano 30, manufactured by Physical Acoustics Inc. Princeton, NJ. Frequency range is $125-750 \mathrm{KHz}$ and resonant frequency is $140 \mathrm{KHz}$.

The AE sensor was placed onto the test piece surface according to the positioning graph (Fig.1). Step loading was applied at $4 \mathrm{kN}$ for each step. Noise and collect signals of micro-damage region were avoided effectively by setting the parameter threshold, preamplifier gain, parameter interval of the software, belock time, and belock time of the software to $35 \mathrm{~dB}, 40 \mathrm{~dB}, 600 \mathrm{us}, 500 \mathrm{us}$, and $600 \mathrm{us,}$ respectively.

\section{Test results and analysis}

\section{Correlation analysis between AE characteristic parameters and bending resistance of NSFC, SFRC, and NC beams in the fracture process}

$\mathrm{AE}$ signal is a complicated waveform that covers abundant information of $\mathrm{AE}$ sources. The $\mathrm{AE}$ signal processing and analysis methods can be divided into two types according to the analysis object. The first is the AE waveform analysis, which refers to methods used to acquire information in $\mathrm{AE}$ signals based on the time-domain waveform of the recorded signal and related frequency spectra and correlation functions, such as FFT method and wavelet transform. The second is the acoustic emission characteristic parameter analysis, which involves a system extracting the characteristic parameters of $\mathrm{AE}$ signals directly by signal analysis and processing technology. Information from $\mathrm{AE}$ sources are acquired based on analysis and evaluation of these parameters. Common parameters include events, amplitude, ringing count, rise time, energy, and duration.

As shown in Fig.2, AE strength suddenly changes at approximately 380 s. Peak AE strength reaches up to $120 \mathrm{~dB}$ and then drops sharply. AE signal disappears at $465 \mathrm{~s}$. As a brittle material, the $\mathrm{NC}$ specimen reaches the maximum load $(24.52 \mathrm{kN})$ at $380 \mathrm{~s}$ and then immediately breaks. Figs. 2-4 shows the TOA-amplitude curves and fracture positioning map of AE during the four-point bending tests of the NC, SFRC, and NSFC beams. NC showed the shortest duration of AE event and NSFC has the longest duration, whereas SFRC is between them. Under the same loading rate, NSFC has longer load-bearing time and significantly higher bending resistance and toughness than the two concretes. Fig.3 shows that the variations of AE amplitude of SFRC with time can be divided into three stages. The first stage is from 0 s to about $280 \mathrm{~s}$, in which the sound signal is relatively weak (about $40 \mathrm{~dB}$ ) and discontinuous, indicating that AE occurs in concrete under low stress. However, stresses inside concrete during the early loading period are small and are less likely to develop into cracks in concrete. During this period, AE signals may come from initial defects and stressed deformation of microcracks. When loading continues and enters into the second stage, AE signals strengthen gradually and their amplitude increases gradually. The steel fiber and concrete substrate work together to bear loads, and thus, microcracks in the concrete are relatively stable and develop slowly. However, with the continuous increase of loads, cracks develop and extend continuously, causing intensely strong AE signals $(40-60 \mathrm{~dB})$. When the load increased to the ultimate at $758 \mathrm{~s}$, concrete deformation increased suddenly, and the corresponding arrival time-amplitude curve of AE displayed a sudden peak. The sound signal amplitude sharply increased to 320dB. Next, it entered the third stage when AE signals are discontinued and only lasted for about 300s. This result is because of the existence of steel fibers crossing cracks that can increase toughness of the concrete. Although an increasing amount of steel fibers can be pulled out from the substrate as loading continues, the concrete is only cracked, but not broken.

Fig. 4 shows that nano $\mathrm{SiO}_{2}$ enhances the characteristics of $\mathrm{AE}$ signals. The variation of the tested AE amplitude of the NSFC beam can be divided into three stages. The duration of the second stage is significantly longer than those of NC and SFRC. Moreover, the AE signal intensity of NSFC is considerably higher than those of NC and SFRC. The AE signal strength of NSFC, which is within the range of $50-80 \mathrm{~dB}$, is higher than that of SFRC. NSFC can endure a longer loading process in the experiment, thereby indicating that nano $\mathrm{SiO}_{2}$ significantly enhances AE signals. Nano $\mathrm{SiO}_{2}$ compacts the transition region between steel fibers and concrete, and thus, the cohesion between steel 
fibers and the substrate is enhanced, and their collaborative effect is maximized. The comparison between Figs. 5 and 6 suggest that the critical load of the bending failure of NSFC $(39.64 \mathrm{kN})$ is $8.84 \%$ higher than that of SFRC. As the load is increased, the AE signal strength of NSFC is intensified. This finding proves that the different variation characteristics of the AE signals are strongly related to the external load, internal microcrack development, and stressed deformation of a concrete structure. Nano $\mathrm{SiO}_{2}$ significantly enhances the characteristics of AE signals. Therefore, the dynamic development of the internal cracks of concrete materials can be predicted by analyzing the correlation between AE characteristic parameters and concrete damages, as well as by examining the variations of $\mathrm{AE}$ characteristic parameters, thereby facilitating damage warning. These findings are beneficial for the non-destructive monitoring of concrete structures.
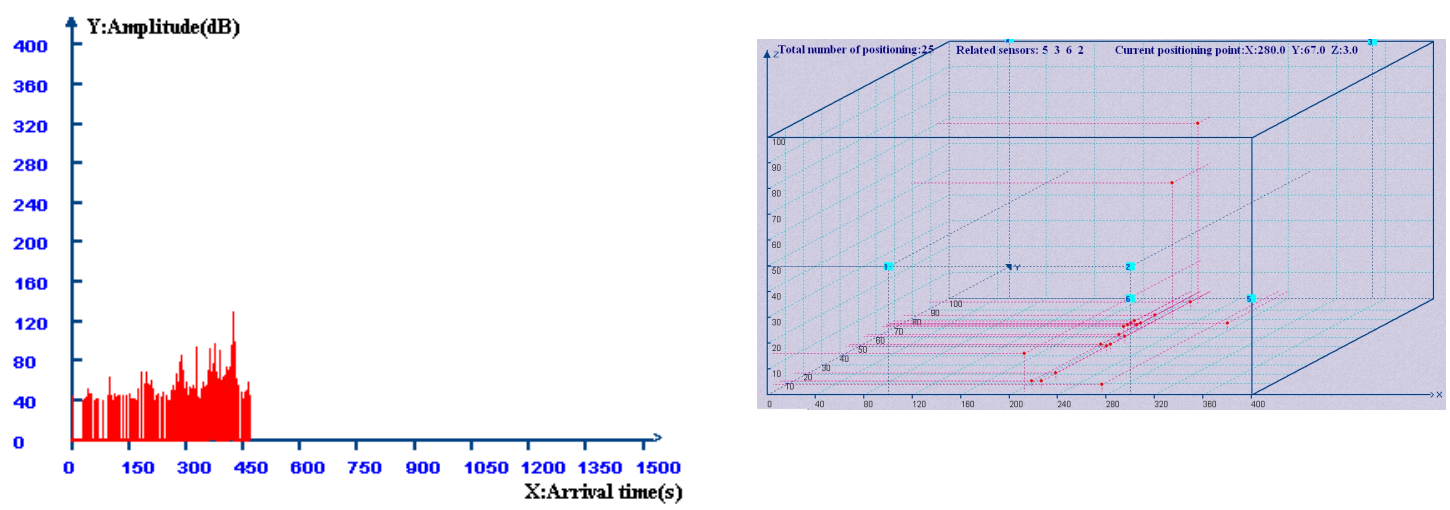

Fig.2 Acoustic emission arrival time - amplitude curve and fracture position image of $\mathrm{NC}$ beam bending test.
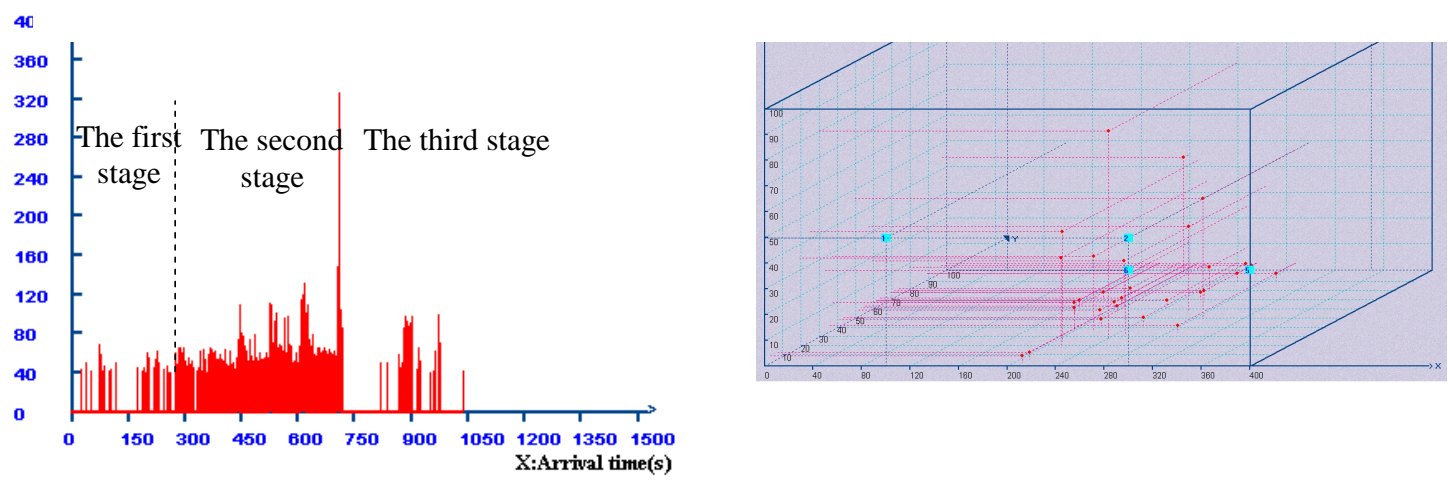

Fig.3 Acoustic emission arrival time - amplitude curve and fracture position image of SFRC beam bending test.
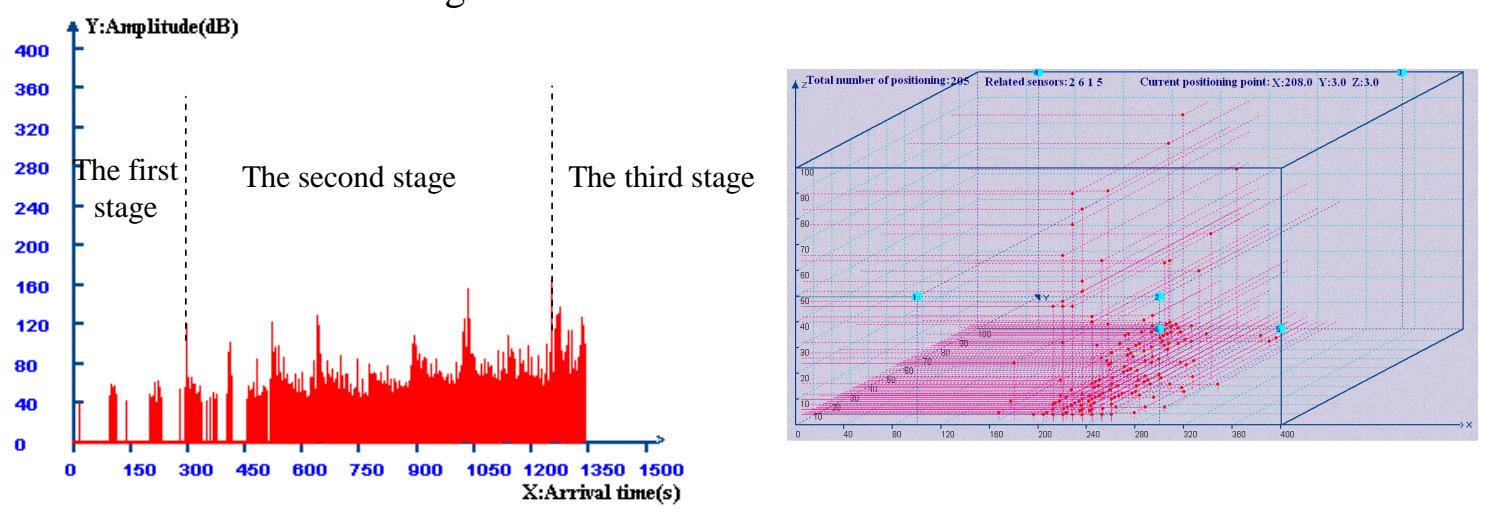

Fig.4 Acoustic emission arrival time - amplitude curve and fracture position image of NSFC beam bending test. 


\section{Damage evaluation}

Concrete fracture caused by external loads is a complex problem. Concrete fracture absorbs a certain amount of energy, and internal structural failure is an energy conversion process. Thus, fracture energy is frequently used to characterize the mechanical properties of concrete[9-13].A high fracture energy of concrete results in considerable fracture toughness and maximum tensile strain, and vice versa. In the four-point bending test based on $\mathrm{AE}$, the fracture energy of concrete can be measured from the area formed by the TOA-energy curves (Fig. 5).

Then, the calculation formula for fracture energy can be derived from the TOA-energy curves as follows:

$$
W=\int E \cdot d T
$$

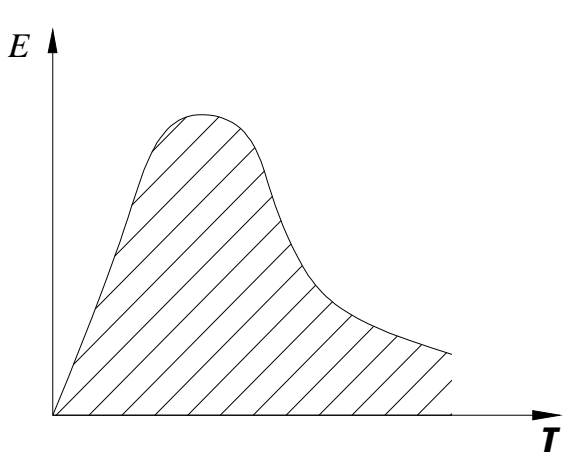

Fig.5 Energy- Arrival time curve of concrete

In this formula, $\mathrm{W}$ is the total energy of $\mathrm{AE}$ signals during fracture damage of concrete specimen.; $\mathrm{E}$ is energy; $\mathrm{T}$ is arrival time.

The area of the TOA-energy curves of the concrete beam specimens indicates the total energy of AE signals during fracture damage. This total energy is composed of two parts: (1) the energy of AE signals produced by elastic deformation at the initial loading of the concrete, and (2) the energy of AE signals produced by concrete fracture. Figs. 6-7 show the TOA-energy and load-displacement curves of the NSFC and SFRC beams during the bending tests. The initial cracking points of a specimen can be identified from the sharp change points of the energy (point "1" in Figs. 6-7). The fracture energy of the specimens can be calculated on this basis, thereby showing how AE characteristic parameters are correlated with load and displacement in the four-point bending tests.

Under general conditions, fracture energy in the AE test is calculated using Equation (1). The area of the TOA-energy curves in the bending tests is calculated via the integral method; these curves represent the total energy of AE signals during the fracture process of the specimens. However, such calculation method will influence the accuracy of the test results to a certain extent. In this study, the initial cracking point was used as the starting point of the load-displacement curve, and the area of the TOA-energy curves after the initial cracking point was calculated via the integral method (Figs. 6-7). Consequently, the fracture energy of AE signals is corrected. Table 3 lists the calculated results of fracture energy after the correction of typical NSFC and SFRC beam specimens.

As shown in Table 3 and Figs. 6-7, the energy jump of AE signals reflects abrupt changes in the loads and displacements of a specimen. The first change point on the TOA-energy curves corresponds to the load and displacement of the initial cracking point on the load-displacement curve. Maximum energy corresponds to the critical load of bending failure. The NSFC specimens developed cracks at a later time than the SFRC specimens. The AE energy at the initial cracking time was 3503 $\mathrm{mv} \cdot \mu \mathrm{m}$, and the corresponding initial cracking load was $15.78 \mathrm{kN}$. The NSFC specimens reached their ultimate loads of bending failure at a loading of $39.64 \mathrm{kN}$. The time from the initial cracking to the ultimate loads of bending failure was $1,045 \mathrm{~s}$, which was significantly longer than those for the SFRC specimens. In the AE tests, the NSFC specimens achieved the highest total AE energy $\left(\mathrm{E}_{1}=\right.$ $7,881,515 \mathrm{mv} \cdot \mu \mathrm{m} \cdot \mathrm{s})$ after the initial cracking point and the highest total fracture energy $\left(\mathrm{E}_{2}=\right.$ $8,482,050 \mathrm{mv} \cdot \mu \mathrm{m} \cdot \mathrm{s}) . \mathrm{E}_{1}$ accounts for $92.92 \%$ of $\mathrm{E}_{2}$. These findings show that nano $\mathrm{SiO}_{2}$ improves the structure and properties of the substrate structure and the transition region of concrete structures, eliminates the interface and the adverse impacts of the interface, and significantly enhances AE signal strength. All of these achievements contribute to the accurate determination of the initial cracking 
point. Compared with the SFRC structures, the NSFC structure displays greater toughness, better durability, and stronger bending resistance.

\section{Conclusions}

(1) Variations in AE signals are related closely with external loading conditions, internal microcrack generation, and development as well as stressed deformation of concrete. Sudden changes in the $\mathrm{AE}$ process form the external presentation of unstable crack extension during the breaking process of materials. AE test results indicate that AE signals are stable. AE signals strengthen as the load increases, a characteristic that can be used to determine initial cracking point, initial cracking load, and ultimate bearing capacity of beams to send early warnings of possible structural failures.

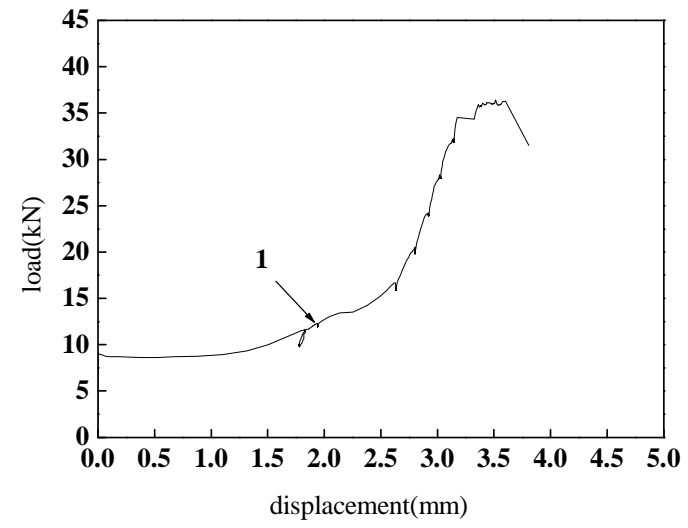

(a) Bending load-displacement curve

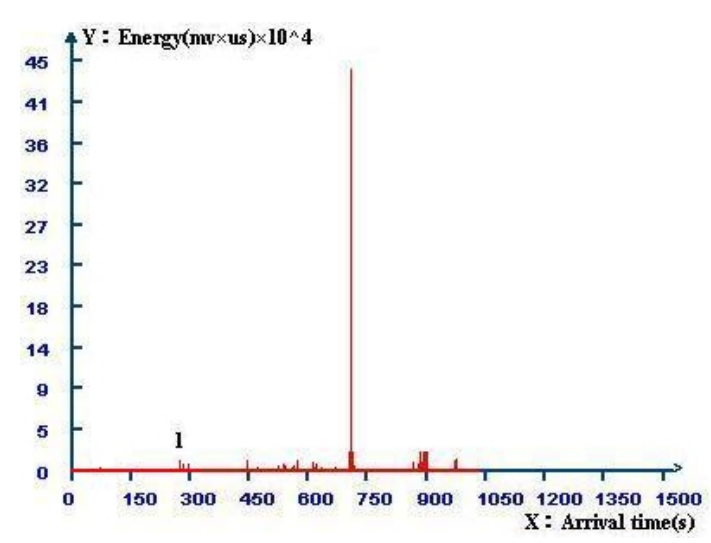

(b) Acoustic emission arrival time - energy curve

Fig.6 Acoustic emission arrival time - energy curve and Bending load-displacement curve of SFRC beam

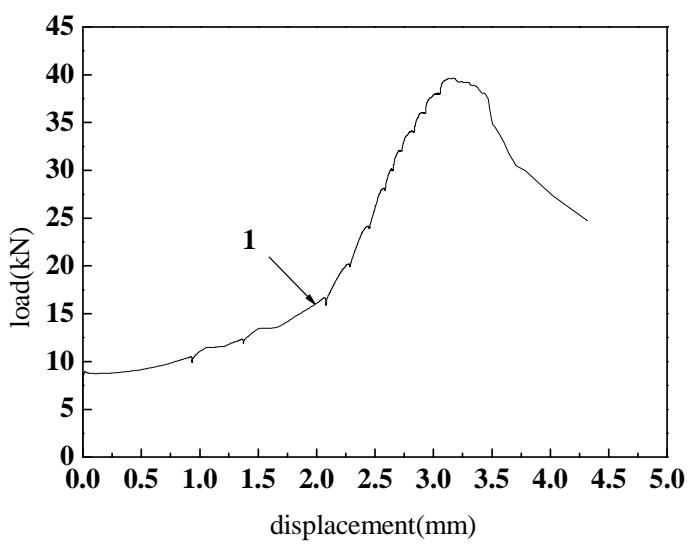

(a) Bending load-displacement curve

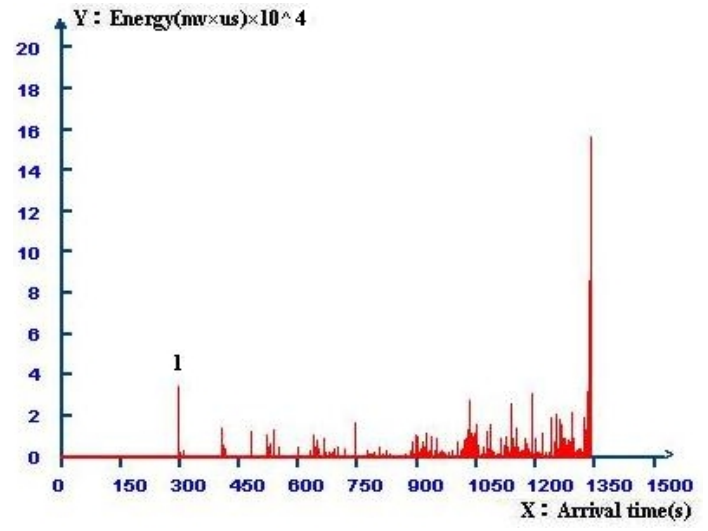

(b) Acoustic emission arrival time - energy curve

Fig.7 Acoustic emission arrival time - energv curve and Bending load-displacement curve of NSFC beam 
Table 3 Fracture energy of NSFC/SFRC/NC beam specimen

\begin{tabular}{ccc}
\hline & SFRC & NSFC \\
\hline Time of initial cracking & $259 \mathrm{~s}$ & $281 \mathrm{~s}$ \\
\hline Initial cracking load $[\mathrm{kN}]$ & 12.04 & 15.78 \\
\hline AE energy at initial cracking $[\mathrm{mv} \cdot \mu \mathrm{m}]$ & 375 & 3503 \\
\hline Ultimate loads of bending failure $[\mathrm{kN}]$ & 36.42 & 39.64 \\
\hline $\mathrm{E}_{1}=$ total energy of AE events after the & 1011060 & 7881515 \\
\hline $\mathrm{E}_{2}=$ total energy of AE events $[\mathrm{mv} \cdot \mu \mathrm{m} \cdot \mathrm{s}]$ & 1635260 & 8482050 \\
\hline $\mathrm{E}_{1} / \mathrm{E}_{2}$ & $61.83 \%$ & $92.92 \%$ \\
\hline
\end{tabular}

(2) The density and duration of AE signals have a monotonously increasing relationship with concrete strength. The effects of steel fiber on a concrete structure are not limited to the post-cracking stage. The use of steel fiber enhances the initial cracking strength of concrete, and the addition of nano $\mathrm{SiO}_{2}$ significantly increases the strength of $\mathrm{AE}$ signals, thereby facilitating the determination of the initial cracking point. Moreover, NSFC possesses greater toughness and stronger bending resistance than SFRC.

(3) Sudden changes in AE signal energy reflect the sudden changes of loads and displacements. The first sudden change point on the arrival time-energy curve corresponds to the load and displacement of the initial cracking point on the load-displacement curve. The maximum energy corresponds to the ultimate bearing capacity. Therefore, stress and damage of concrete structures can be determined accurately based on the arrival time-energy curve of $\mathrm{AE}$.

\section{Acknowledgements}

This work was supported by the National Natural Science Foundation of China (Grant No. 11362006).

\section{References}

[1] D.G. Aggelis, D.V. Soulioti, N. Sapouridis. Acoustic emission characterization of the fracture process in fibre reinforced concrete. Construction and Building Materials, (25):4126-4131,(2011)

[2] Arash Behnia , Hwa Kian Chai, Tomoki Shiotani. Advanced structural health monitoring of concrete structures with the aid of acoustic emission. Construction and Building Materials, (65) 282-302,( 2014)

[3] GROSSE C U, OHTSU M. Acoustic Emission Testing. Berlin: Springer, (2008).

[4] Zhu Hongping, Xu Wensheng, Chen Xiaoqiang. Quantitative Concrete-Damage Evaluation by Acoustic Emission Information and Rate-Process Theory. Engineering Mechanics,25(1):186-191. (2008)

[5] Chen Bingrui, Feng Xiating, Xiao Yaxun. Acoustic Emission Test on Damage Evolution of Surrounding Rock in Deep-Buried Tunnel During TBM Excavation. Chinese Journal of Rock Mechanics and Engineering , 29 (8):1562-1569. (2010)

[6] Xu Bing. Application technology of Nano-materials. Beijing: Chemical Industry Press (2004)

[7] Lan Yan, YongMing Xing, Jing Zhang, JiJun Li. High-temperature mechanical properties and microscopic analysis of nano-silica steel fibre RC. Magazine of Concrete Research.,65(24):1472-1479.( 2013)

[8] Ji Hongguang PEI Guangwen SHAN Xiaoyun. Technique of acoustic emission for concrete material. Applied Acoustics , 21(4):1-5.( 2002) 
[9] Doon-Jin Yoon,W.Jason Weiss,Surendra P.Shah.Assessing damage in corroded reinforced concrete using acoustic emission.Journal of Engineering Mechanics,

Vol.126,No.3:273-281(2000)

[10] XU S L,ZHANG X F.Determination of fracture parameters for crack propagation in concrete using an energy approach.Eng Fract Mech ,75(15):4292-4308.( 2008)

[11] KUMAR S, BARAI S V.Influence of specimen geometry on determination of double-K fracture parameters of concrete: a comparative study.Int J Fract, 149(1):47-66.( 2008)

[12] Zhao ZHiFang, Zhang XiaoGang, Zhou HouGui.Experimental study for determining double_K fracture parameters of the Three Gorges Dam concrete.Journal of ShengZhen University Science and Engineering.,24(4):363-367.( 2007)

[13] RAO G A, PRASAD B K.Fracture energy and softening behavior of high-strength concrete.Cem Concr Res, 32:247-252.( 2002) 